\title{
Steganografi Pada Digital Image Menggunakan Metode Least Significant Bit Insertion
}

\author{
Siti Nur'aini ${ }^{1}$ \\ 1Universitas Islam Negeri Walisongo Semarang
}

\begin{abstract}
Steganography is a way to hide messages or confidential data in a medium called a carrier file. In this study steganography is performed using the Least Significant Bit Insertion method, which is to replace the lowest bits of Red Green Blue (RGB) each pixel with the data bits that you want to insert. From the results of this study it can be seen that steganography can be performed by the Least Significant Bit Insertion method. This method causes the color difference between pixels that have not been pasted by messages and pixels that have been pasted by messages. The size of the change or degradation of color depends on the number of characters inserted. The more characters that are inserted the more visible color degradation that occurs. In using the Least Significant Bit Insertion method, it is necessary to consider the type of digital image format used, this is necessary to avoid the loss of messages when extracting. The best digital image format used is the 24-bit BMP because the BMP format is lossless compression.
\end{abstract}

Keyword: Embedding, extracting, least significant bit, steganography.

\begin{abstract}
Abstrak
Steganografi adalah suatu cara untuk menyembunyikan pesan atau data rahasia di dalam suatu media yang disebut carrier file. Pada penelitian ini steganografi dilakukan dengan menggunakan metode Least Significant Bit Insertion yaitu mengganti bit yang paling rendah dari Red Green Blue (RGB) setiap pixel dengan bit data yang ingin disisipkan. Dari hasil penelitian ini terlihat bahwa steganografi dapat dilakukan dengan metode Least Significant Bit Insertion. Metode ini menyebabkan perbedaan warna antara pixel yang belum disisipi pesan dan pixel yang telah disisipi pesan. Besar kecilnya perubahan atau degradasi warna tersebut tergantung dari jumlah karakter yang disisipkan. Semakin banyak karakter yang disisipkan akan semakin terlihat degradasi warna yang terjadi. Pada penggunaan metode Least Significant Bit Insertion perlu dipertimbangkan jenis format digital image yang digunakan, hal ini diperlukan untuk menghindari hilangnya pesan pada waktu extracting. Format digital image yang paling baik digunakan adalah bmp 24-bit karena format bmp ini bersifat lossless compression.
\end{abstract}

Kata kunci: Embedding, extracting, least significant bit, steganografi.

ISSN 2715-0143 (online) ISSN 2714-9048 (print)

http://journal.walisongo.ac.id/index.php/jit/index 


\section{Pendahuluan}

Saat ini internet sudah berkembang menjadi salah satu media yang paling populer di dunia. Karena fasilitas dan kemudahan yang dimilikinya maka internet untuk saat ini sudah menjadi barang yang tidak asing lagi. Sayangnya dengan berkembangnya internet dan aplikasi menggunakan internet, semakin berkembang pula kejahatan sistem informasi. Dengan berbagai teknik, banyak yang mencoba untuk mengakses informasi yang bukan haknya. Maka dari itu, sejalan dengan berkembangnya media internet ini harus juga diikuti dengan perkembangan pengamanan sistem informasi.

Berbagai macam teknik digunakan untuk melindungi informasi yang dirahasiakan dari orang yang tidak berhak, salah satunya adalah teknik steganografi. Berbeda dengan teknik kriptografi, steganografi menyembunyikan pesan rahasia agar orang awam tidak menyadari keberadaan dari pesan yang disembunyikan. Teknik ini sering digunakan untuk menghindari kecurigaan orang dan menghindari keinginan orang untuk mengetahui isi pesan rahasia tersebut. Steganografi membutuhkan dua properti, yaitu media penampung dan data rahasia yang akan disembunyikan, media penampung steganografi dapat berupa image, audio maupun video (Munir, 2006).

Walaupun steganografi dapat dikatakan mempunyai hubungan erat dengan kriptografi, tetapi kedua metode ini sangat berbeda. Semua teknik steganografi konvensional berusaha merahasiakan komunikasi dengan cara menyembunyikan pesan ataupun mengkamuflase pesan. Maka sesungguhnya prinsip dasar dalam steganografi lebih dikonsentrasikan pada kerahasiaan komunikasinya bukan pada datanya.

Dalam peristiwa penyerangan gedung WTC tanggal 11 September 2001 disebutkan oleh pejabat pemerintah dan para ahli dari pemerintahan AS yang tidak disebut namanya bahwa "para teroris menyembunyikan peta-peta dan fotofoto target dan juga perintah untuk aktivitas teroris di ruang chat sport, bulletin boards porno dan website lainnya". Isu lainnya menyebutkan bahwa teroris menyembunyikan pesanpesannya dalam gambar-gambar porno di website tertentu. Dimana teknik penyembunyian pesannya disebutkan dengan menggunakan steganografi (Suyono, 2004). Hal ini membuktikan bahwa steganografi dapat digunakan untuk menyembunyikan pesan.

Steganografi berasal dari bahasa yunani steganos, yang artinya 'tersembunyi/terselubung', dan graphein, 'menulis' sehingga kurang lebih artinya "tulisan terselubung". Steganografi merupakan seni untuk menyembunyikan pesan di dalam pesan lainnya sedemikian rupa sehingga orang lain tidak menyadari ada sesuatu di dalam pesan tersebut. Salah satu proses penyembunyian pesan rahasia 
dalam sistem steganografi dapat dilakukan dengan menggunakan digital image. Digital image ini di sebut sebagai file induk (carrier file) dan digital image yang akan digunakan adalah format bmp 24-bit. Sedangkan image yang telah disisipi pesan disebut stego-image. Metode yang digunakan untuk menyembunyikan pesan yaitu dengan Least Significant Bit Insertion. Steganografi pada digital image digunakan untuk mengeksploitasi keterbatasan kekuatan sistem penglihatan manusia dengan cara menurunkan kualitas warna pada carrier file. Sehingga dengan keterbatasan tersebut manusia tidak akan mencurigai bahwa digital image tersebut telah disisipi pesan rahasia (Sellars, 2009).

\section{Metode}

Metode yang digunakan dalam penelitian ini adalah Least Significant Bit (LSB) Insertion merupakan pendekatan yang sederhana untuk menyembunyikan pesan di dalam suatu carrier file. Metode ini diterapkan pada format image seperti bmp. Prinsip kerja dari metode ini yaitu mengganti LSB dari RGB setiap pixel dengan bit pesan. Stego-image yang dihasilkan nantinya akan terlihat sama dengan gambar sebelum disisipkan karena dalam proses penggantiannya dilakukan pada bit LSB sehingga tidak akan nampak perbedaan yang signifikan pada pixel tersebut. Untuk metode LSB insertion harus digunakan digital image yang bersifat lossless compression hal ini dilakukan untuk menghindari hilangnya pesan yang tersimpan dalam stego-image karena proses kompresi. (Bender, 1996)

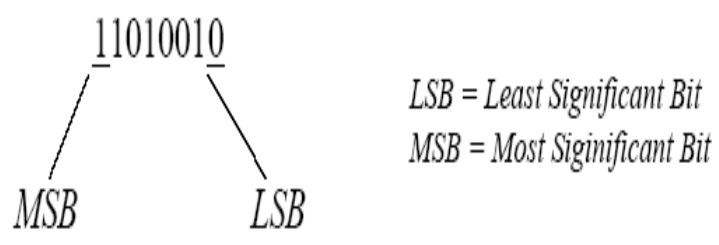

Gambar 2

Susunan bit pada sebuah Byte

$00110011 \quad 10100010 \quad 11100010 \quad 01101111$



Gambar 3

Proses Penyembunyian pesan dengan Metode LSB Insertion

Pada gambar 3 ditunjukan bagaimana proses penyisipan pesan yang dilakukan pada LSB dimana $00110011 \quad 10100010 \quad 11100010$ 01101111 merupakan bit dari carrier file dan 0111 merupakan bit data pesan yang ingin disembunyikan. Dari gambar 3 perubahan tersebut hanya mengubah nilai byte satu lebih tinggi atau satu lebih rendah dari nilai sebelumnya. Misalkan byte tersebut menyatakan 
warna merah, maka perubahan satu bit LSB tidak kelihatan perubahan warna merah tersebut secara berarti dan tidak tampak mata. Agar data tersebut aman sebelum disembunyikan dapat dienkripsi terlebih dahulu (Wijaya, 2004).

\section{Kerangka Teori}

\subsection{Image Digital}

Bagi sebuah komputer, sebuah image adalah sebuah kumpulan angkaangka yang merepresentasikan intensitas cahaya pada bermacam-macam pixel (titik). Digital image biasanya disimpan dalam 24-bit atau 8-bit. 24-bit digital image menyediakan tempat yang lebih untuk menyembunyikan informasi. Semua variasi warna untuk tiap pixel terdiri dari dari 3 warna dasar yaitu RGB. 3 warna dasar yang dijadikan patokan warna secara universal (primary colors). Dengan basis RGB, kita bisa mengubah warna ke dalam kode-kode angka sehingga warna tersebut akan tampil universal di manapun di seluruh dunia ini. Setiap warna dasar direpresentasikan dengan 1 byte, 24 bit gambar menggunakan 3 bytes per pixel untuk merepresentasikan nilai warna.

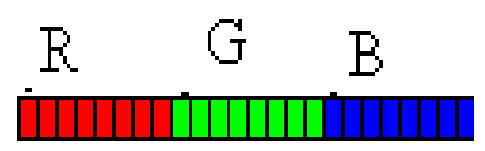

Gambar 1

\section{Susunan RGB pada tiap pixel}

Untuk warna merah murni direpresentasikan dengan: 11111111 0000000000000000 . Untuk hijau murni direpresentasikan dengan: 000000001111111100000000 , dan untuk biru murni direpresentasikan dengan: $00000000 \quad 00000000$ 11111111. Dari uraian di atas dapat dilihat bahwa informasi dari warna biru berada pada bit 0 sampai bit 7 , dan informasi warna hijau berada pada bit 8 sampai dengan bit 15, sedangkan informasi warna merah berada pada bit 16 sampai dengan bit 23 (Batara, 2008).

Sedangkan jenis image yang paling baik untuk menyembunyikan pesan adalah digital image dengan format bmp 24-bit. Alasannya adalah karena format bmp ini adalah jenis digital image yang paling besar ukurannya dan secara otomatis menjadikan kualitas gambarnya menjadi yang paling tinggi. Jika suatu gambar mempunyai resolusi dan kualitas yang tinggi maka untuk melakukan proses penyembunyian pesan akan lebih mudah. Selain itu image dengan tipe bmp bersifat lossless sehingga dalam penyembunyian pesan dapat menggunakan metode $L S B$ insertion. (Suyono, 2004).

\subsection{Steganografi}

Steganografi adalah ilmu dan seni menyembunyikan pesan rahasia 
didalam pesan lain sehingga keberadaan pesan rahasia tersebut tidak dapat diketahui (Munir, 2006). Pengertian lain dari steganografi adalah ilmu, teknik atau seni menyembunyikan pesan rahasia (hidding message) atau tulisan rahasia (covered writing), menjadikan pesan tersebut tidak terbaca orang lain kecuali pengirim dan penerima pesan tersebut. Steganografi awalnya dari bahasa Yunani yakni "steganos" yang artinya tersembunyi/menyembunyikan dan "graphy" yang artinya tulisan yang secara lengkap memiliki arti tulisan yang disembunyikan. Dalam buku Histories of Herodatus steganografi dengan media kepala budak yaitu dengan cara kepala budak dibotaki kemudian ditulisi pesan dan rambut budak tersebut dibiarkan tumbuh selanjutnya budak baru dikirim. Ditempat penerima kepala budak pembawa pesan tersebut digundul supaya pesan dapat terbaca. Pemakaian tinta tak-tampak (invisible ink), tinta dibuat dari campuraan sari buah, susu dan cuka. Tulisan diatas kertas bisa dibaca dengan memanaskan kertas tersebut (Darmawan, 2003).

Pada perang dunia II adalah periode pengembangan teknik - teknik baru steganogafi. Pada awal Perang Dunia II walaupun masih digunakan teknik tinta yang tak terlihat, namun teknik - teknik baru mulai dikembangkan seperti menulis pesan rahasia ke dalam kalimat lain yang tidak berhubungan langsung dengan isi pesan rahasia tersebut, kemudian teknik menulis pesan rahasia ke dalam pita koreksi karbon mesin ketik, dan juga teknik menggunakan pin berlubang untuk menandai kalimat terpilih yang digunakan dalan pesan, teknik terakhir adalah microdots yang dikembangkan oleh tentara Jerman pada akhir Perang Dunia II. Dari contohcontoh steganografi konvensional tesebut dapat dilihat bahwa semua teknik steganografi konvensional berusaha merahasiakan komunikasi dengan cara menyembunyikan pesan ataupun mengkamuflase pesan. Maka sesungguhnya prinsip dasar dalam steganogafi lebih dikonsentrasikan pada kerahasiaan komunikasinya bukan pada datanya (Wijaya, 2004).

Cara kerja atau prinsip dari
steganografi adalah dengan
menggunakan dua unsur untuk
menyisipkan suatu pesan atau data
yang ingin disembunyikan. Unsur
pertama adalah media penampung
seperti citra, suara, video, dan lain
sebagainya yang tidak membuat curiga
bahwa ada pesan rahasia dalam media
tersebut. Unsur kedua adalah pesan
yang hendak disembunyikan (Husni,
2010).

\section{Pembahasan}

\subsection{Embedding Pesan}

Pada proses ini yang pertama kali dilakukan adalah menyediakan carrier file yaitu digital image dengan format bmp 24-bit. Pesan yang disisipkan berupa teks yang diinputkan melalui keyboard. Sebelum dilakukan 
penyisipan pesan, carrier file diperiksa apakah sudah terdapat pesan yang telah disembuyikan atau belum. Jumlah karakter yang bisa disisipkan tergantung dari ukuran image. Semakin besar ukuran image maka semakin banyak pula karakter pesan yang bisa disisipkan. Untuk menyisipkan 1 karakter diperlukan 3 pixel. Dimana dengan perhitungan sebagai berikut: 1 karakter direpresentasikan dengan 8 bit biner. Sedangkan 1 pixel terdiri dari 24 bit. Sehingga 1 pixel mampu menampung 3 bit dari karekter yang akan disisipkan. Perhitungan untuk karakter maksimal yang dapat disisipkan adalah:

$$
\text { (width* (height }-1) * 3 \text { ) / } 8 \text {. }
$$

Jadi jika ada sebuah digital image dengan ukuran 300x250 pixel dapat digunakan untuk menyisipkan karakter sebanyak 28012 karakter. Pada persamaan (1) untuk height harus dikurangi 1 . Hal ini disebabkan karena harus disediakan 1 pixel untuk menyimpan kode tertentu yang menunjukkan bahwa suatu digital image sudah terisi pesan atau belum.

Contoh penyisipan karakter Z yang direpresentasikan $01011010 \quad$ pada carrier file:

$$
\begin{array}{cc}
0000101 \underline{1} & 1111100 \underline{0} \\
1111010 \underline{0} & \\
1110000 \underline{1} & 1011000 \underline{0} \\
1010111 \underline{1} \\
0101000 \underline{0} & 1011111 \underline{1} \\
0101001 \underline{0}
\end{array}
$$

Maka stego-image yang dihasilkan adalah sebagai berikut:

$$
\begin{array}{cc}
0000101 \underline{\mathbf{0}} & 1111100 \underline{\mathbf{1}} \\
1111010 \underline{0} \\
1110000 \underline{1} \quad 1011000 \underline{\mathbf{1}} \\
1010111 \underline{\mathbf{0}} \\
0101000 \underline{1} 1011111 \underline{\mathbf{0}} \\
0101001 \underline{0}
\end{array}
$$

Pada bit-bit yang digarisbawahi adalah LSB dari masing-masing komponen RGB. Sedangkan yang dicetak tebal adalah LSB yang mengalami perubahan. Setelah pesan disisipkan. Maka langkah berikutnya adalah menyisipkan koordinat pixel dimana karakter terakhir disisipkan. Informasi lokasi ini berguna agar dalam proses extracting pesan rahasia dari image bisa tepat dalam mengambil bit-bit biner.

\subsection{Extracting}

Pada proses extracting yang perlu dilakukan pertama kali adalah memeriksa keberadaan kode. Jika terdapat kode tertentu maka dapat dipastikan bahwa digital image tersebut mempunyai pesan di dalamnya. Langkah berikutnya adalah mengambil koordinat terakhir dimana karakter disimpan, hal ini diperlukan untuk menghindari pengambilan bit pada koordinat yang kurang tepat. Informasi lokasi ini berguna agar dalam 
proses extracting pesan rahasia dari stego-image, program bisa tepat dalam mengambil bit-bit biner pesan, sehingga program bisa berhenti ketika bit-bit biner pesan telah habis diambil.
Informasi koordinat ini berfungsi sebagai pembatas dalam looping pada proses ambil pesan, sehingga ketika sampai pada koordinat terakhir proses extracting bisa berhenti. Adapun diagram alir secara umum ditunjukkan pada gambar 5 .

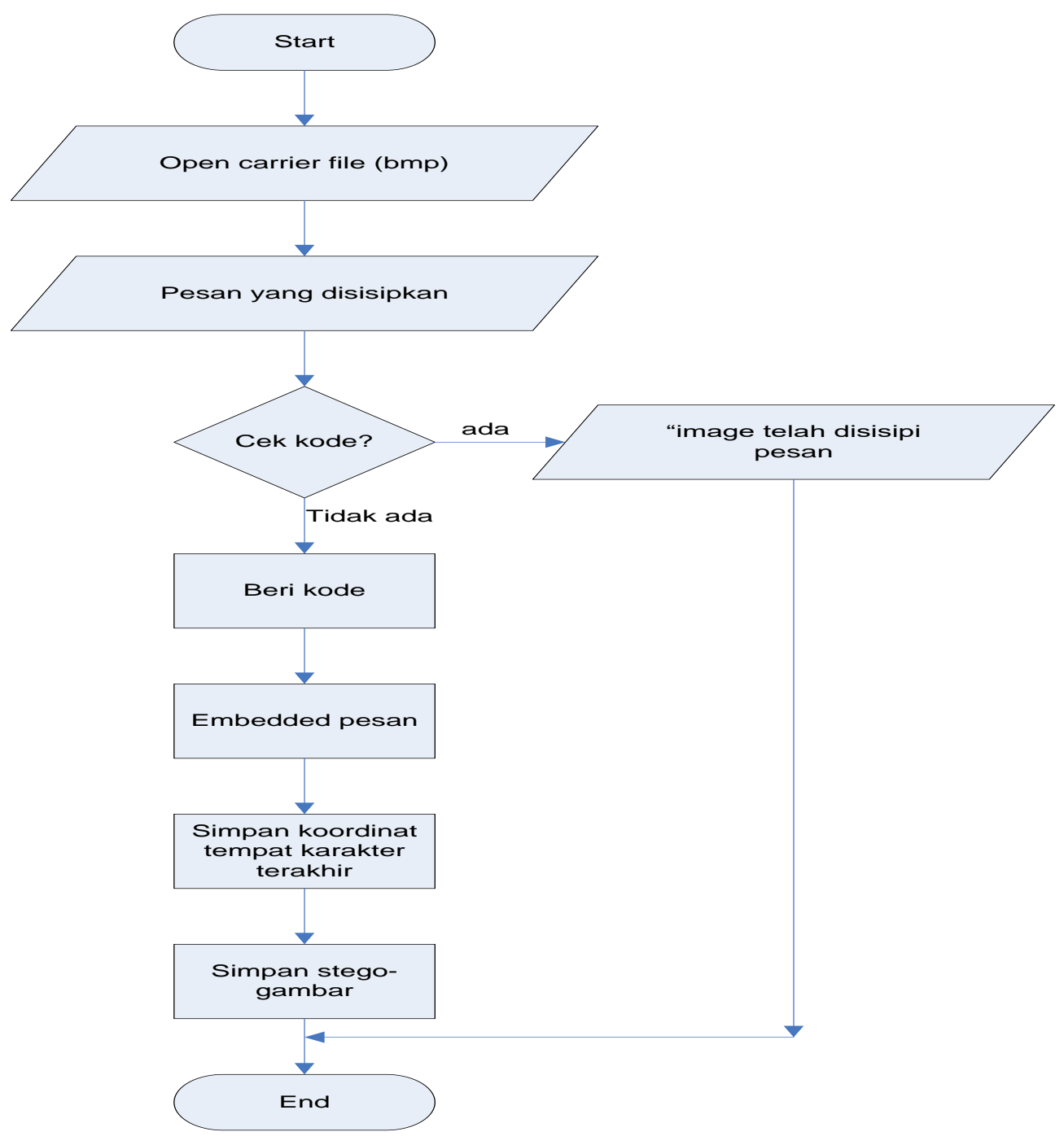

Gambar 4 
Diagram alir proses embedding pesan secara umum

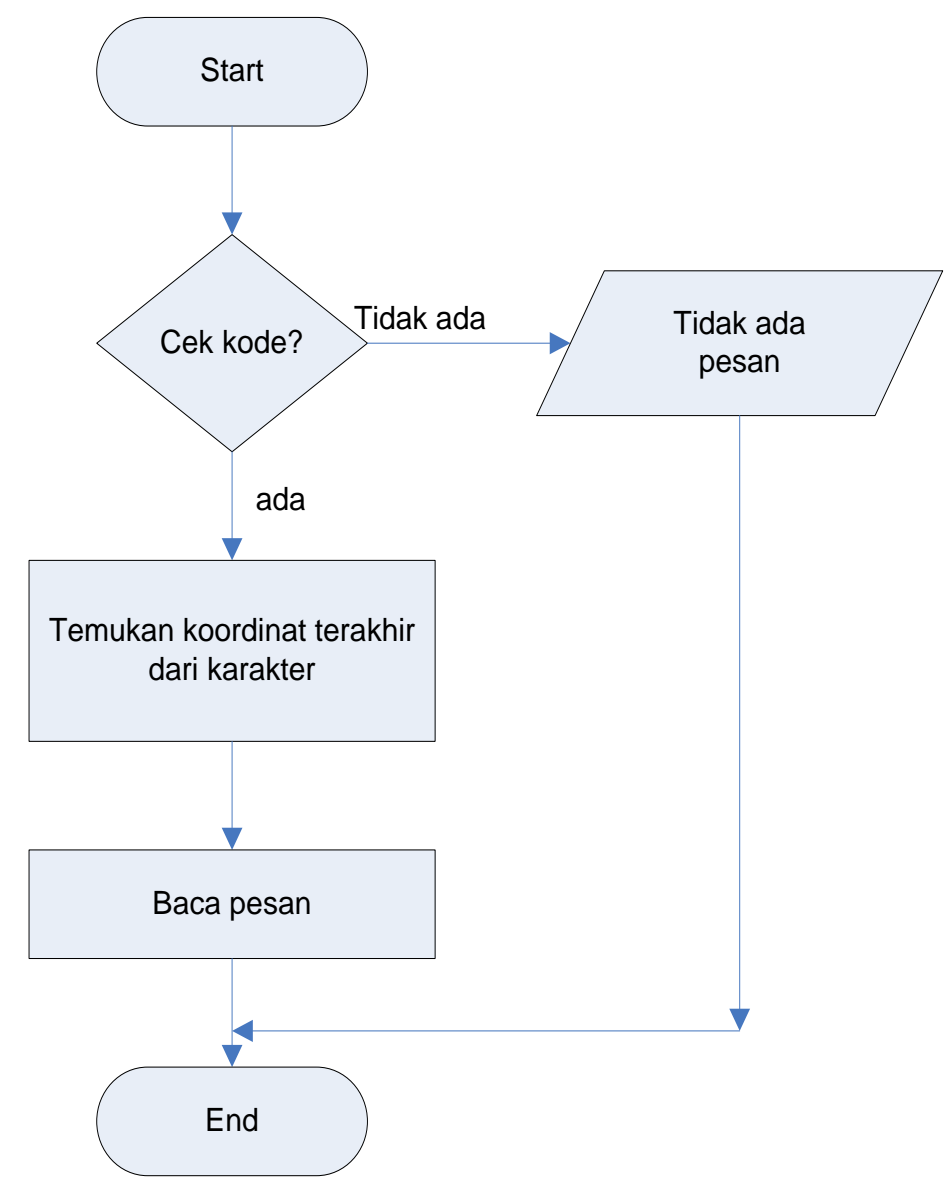

Gambar 5

Diagram alir proses extracting secara umum

\subsection{Pengujian}

Pengujian menggunakan 3 digital image dengan format bmp 24-bit yang berbeda dan pesan yang berbeda pula. Sebelum proses embedding dan setelah proses embedding akan diperiksa bagaimana histogram dari masing-masing image. Histogram ini digunakan untuk mengetahui tingkat RGB dari masingmasing pixel.

Image 1 adaah digital image dengan ukuran 295x200 pixel. Image pada gambar 6 berfungsi sebagai carrier file. Adapun pesan yang ingin 
disembunyikan adalah: "lihat diketahui bahwa tidak terjadi degradasi perbedaannya”, yaitu sebanyak 18 warna. Sehingga orang awam yang karakter. Sedangkan pada gambar 7 melihat image tersebut tidak akan adalah image 1 setelah proses embedding. menyadari adanya pesan yang Dari hasil gambar dan histogram yang ada disembunyikan pada image tersebut. pada gambar 6 dan gambar 7, dapat

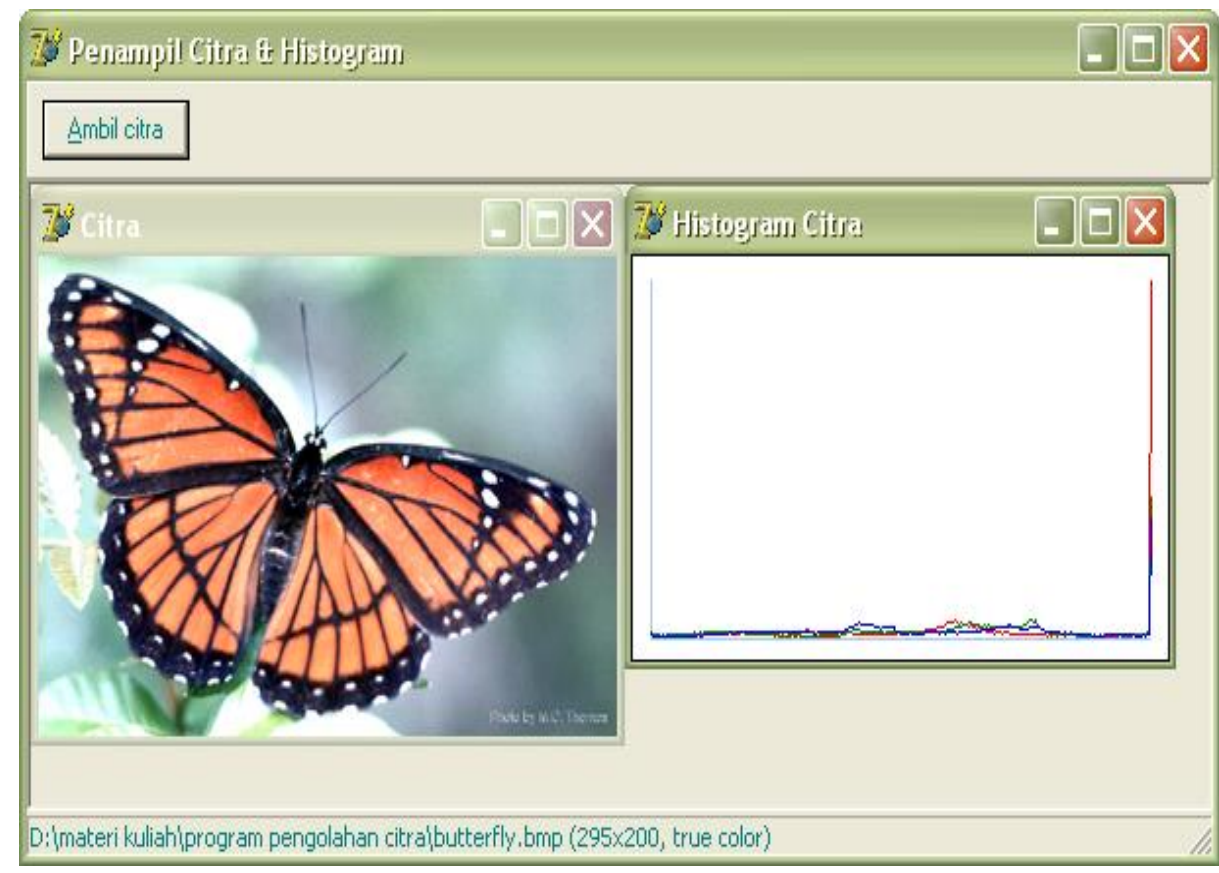

Gambar 6

Image 1 sebelum proses embedding 




Gambar 7

Image 1 setelah proses embedding

Image 2 berukuran 300x202 pixel. Image pada gambar 8 berfungsi sebagai carrier file. Pesan yang disisipkan sebanyak 5778 karakter. Sedangkan pada gambar 9 adalah image 2 setelah disisipi pesan. Dari carrier file dan stego-image serta histogram yang dihasilkan dari masing-masing image, dapat diketahui bahwa terjadi degradasi warna pada bagian atas stego-image. Karena terjadi degradasi warna tersebut menyebabkan kecurigaan pada orang yang melihatnya.

Image 3 dengan ukuran 169x199 pixel. Image pada gambar 10 tersebut berfungsi sebagai carrier file. Pesan tersebut sebanyak 12548 karakter. Sedangkan pada gambar 10 adalah image 2 setelah dilakukan proses embedding. Dari carrier file dan stegoimage serta histogram yang dihasilkan dari masing-masing image, dapat diketahui bahwa terjadi degradasi warna pada seluruh bagian stegoimage. 
Steganografi Pada Digital Image Menggunakan Metode Least Significant Bit Insertion

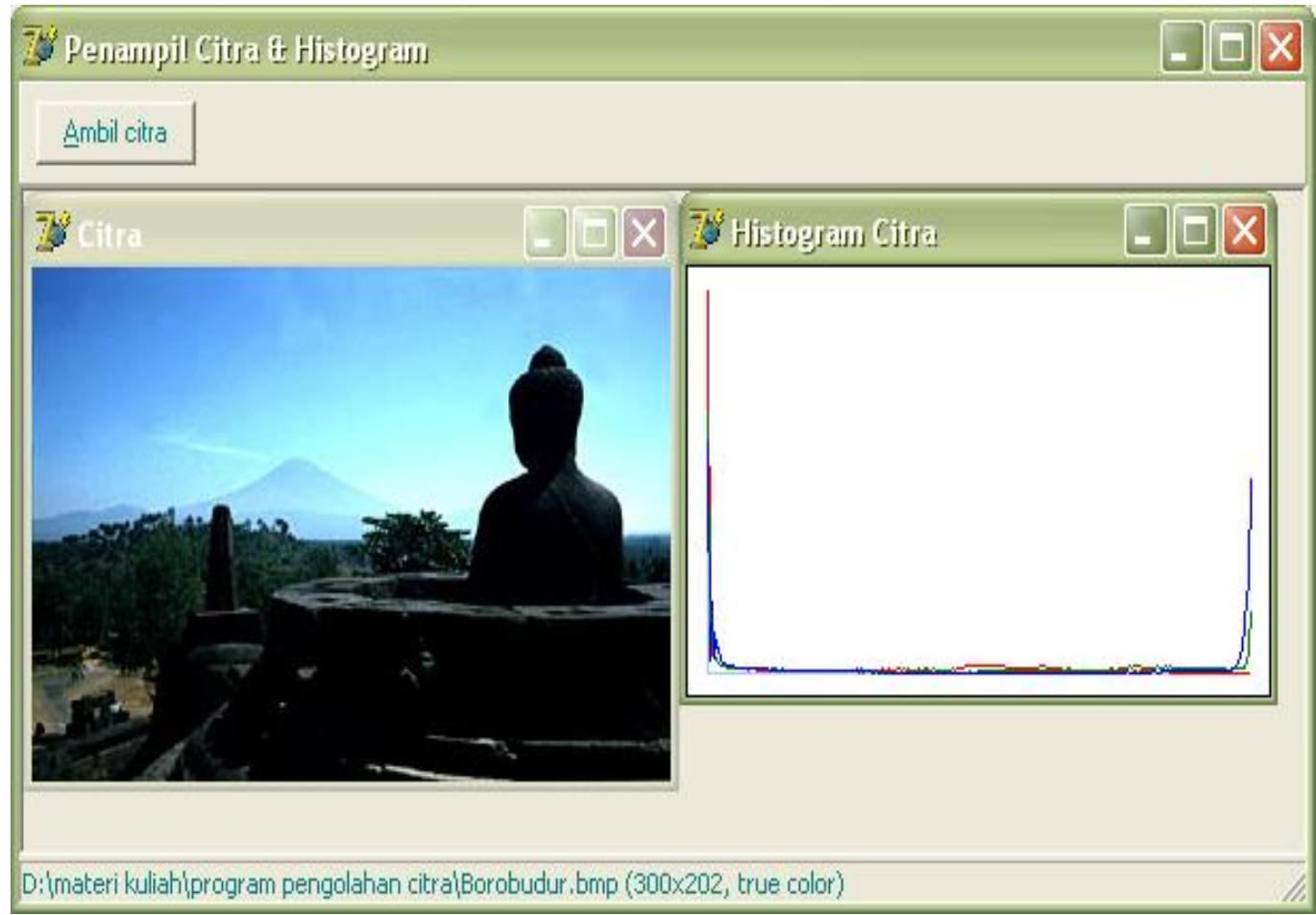

Gambar 8 : Image 2 sebelum proses embedding 


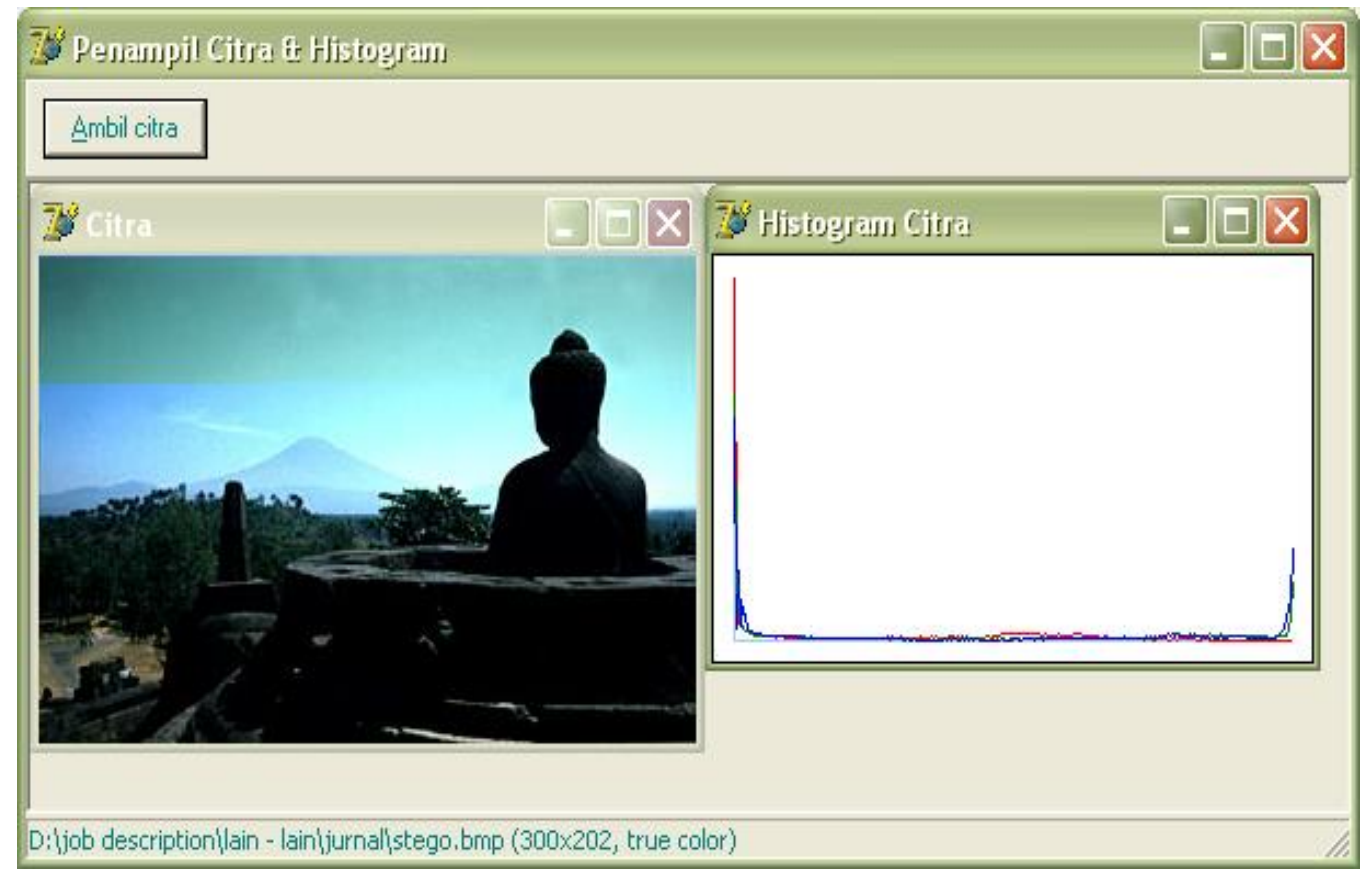

Gambar 9 : Image 2 setelah proses embedding

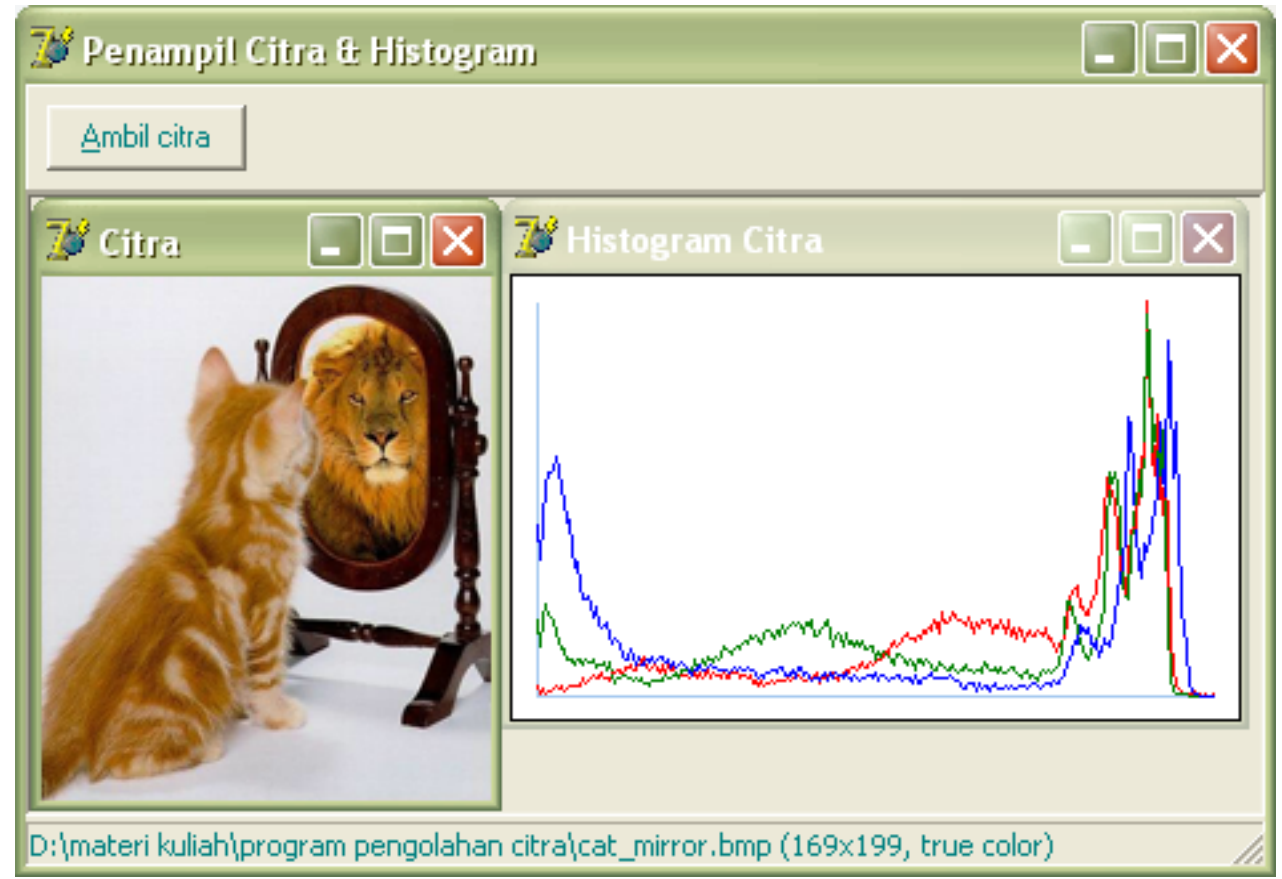

Gambar 10

Image 3 sebelum proses embedding 


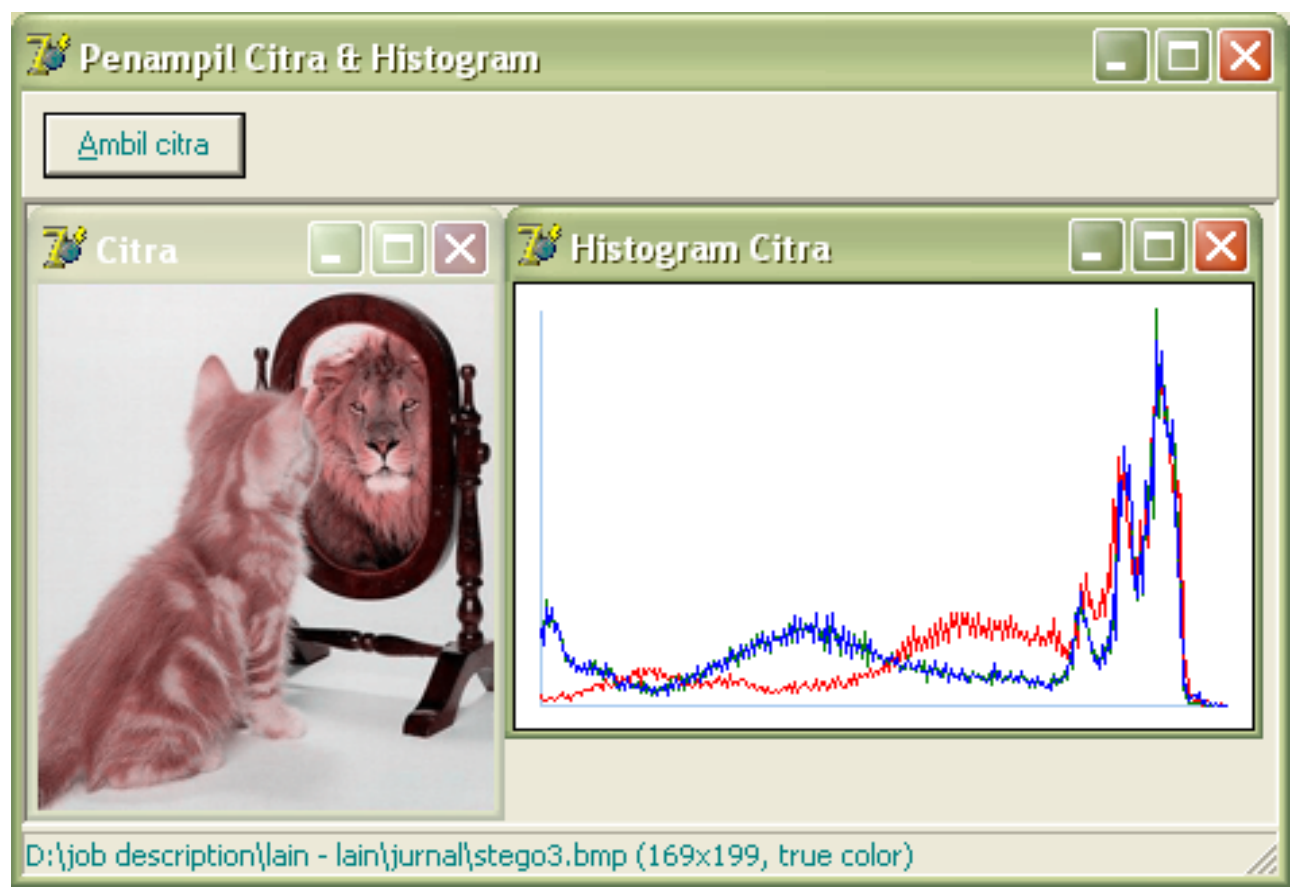

Gambar 11

Image 3 setelah proses embedding

Tabel 1

Hasil pengujian

\begin{tabular}{|l|l|l|l|c|}
\hline Image & Ukuran (pixel) & Karakter Max & Karakter terpakai & sisa \\
\hline Image 1 & $295 \times 200$ & 22014 & 18 & 21996 \\
\hline Image 2 & $300 \times 202$ & 22612 & 5778 & 16834 \\
\hline Image 3 & $169 \times 199$ & 12548 & 12546 & 2 \\
\hline
\end{tabular}

Tabel 1 menunjukkan informasi yang dihasilkan oleh program steganografi dengan berbagai ukuran image sebagai carrier file dan banyaknya pesan yang disisipkan. Pada image 1 space tersisa yang tidak disisipi pesan sangat banyak yaitu sebesar 21996, sedangkan pada image 3 space yang tersisa hanya 2. Dari
3 hasil pengujian dengan berbagai ukuran carrier file dan jumlah karakter yang disisipkan terlihat bahwa steganografi dapat dilakukan dengan metode LSB insertion. Metode ini menyebabkan adanya perubahan warna pada carrier file. 


\section{Kesimpulan}

Berdasarkan hasil penelitian terlihat bahwa steganografi dapat dilakukan dengan menggunakan carrier file berupa digital image berformat bmp 24-bit dengan metode LSB insertion. Metode LSB insertion mengubah RGB setiap pixel dengan bit pesan. Metode ini menyebabkan adanya perubahan atau degradasi warna pada carrier file. Besar kecilnya perubahan atau degradasi warna tersebut tergantung dari jumlah karakter yang disisipkan. Semakin banyak karakter yang disisipkan akan semakin terlihat degradasi warna yang terjadi. Hal ini dapat menimbulkan kecurigaan sehingga untuk ke depan perlu dikembangkan metode atau algoritma steganografi yang lebih meminamalisir degradasi warna tersebut. 


\section{DAFTAR PUSTAKA}

Batara, S. (2008). Studi Steganografi dalam File Mp3.

Bender. (1996). Techniques For Data Hiding. IBM Systems Journal.

Darmawan. (2003). Steganography Sebuah Pendekatan Baru dalam Pengamanan Data.

Husni. (2010). Keamanan komputer. Universitas Trunojoyo.

Munir, R. (2006). Diktat Kuliah Kriptografi. Institut Teknologi Bandung.

Sellars, D. (2009). An Introduction to Steganography.

Suyono. (2004). Penyerangan Pada Sistem Steganografi Dengan Menggunakan Metode Visual Attacks dan Statistical Attacks.

Wijaya, E. S. (2004). Konsep Hidden Message Menggunakan Teknik Steganografi. Media Informatika, 2. 
This page intentionally left blank.

90 | WJIT : Walisongo Journal of Information Technology -Vol.1 No. 1 (2019) 